\title{
Evaluation of antioxidant capacity of polysaccharide in Jerusalem artichoke (Helianthus tuberosus L.) during overwintering
}

\author{
Hong-li Zhou ${ }^{1, *}$, Bing $\mathrm{Li}^{2}$, Mei-fu $\mathrm{Wu}^{2}$, and Ye Liu ${ }^{1}$ \\ ${ }^{1}$ Engineering Research Center for Agricultural Resources and Comprehensive Utilization of Jilin Provence, \\ Jilin institute of chemical technology, Jilin, China \\ ${ }^{2}$ Graduate School, Jilin institute of chemical technology, Jilin, China
}

\begin{abstract}
To determine the effect of different harvesting time on antioxidant capacity in Jerusalem artichoke polysaccharides (inulin), the Jerusalem artichoke before and after overwintering were collected from the same region, and then evaluate their antioxidant capacity in vitro by reducing power assay, DPPH radical-scavenging assay and hydroxyl radical-scavenging assay. Ascorbic acid at similar mass concentration was served as positive control. The results showed no significant difference were observed in reducing power when the absorbance values were about 0.3 . When the mass concentrations before and after overwintering were $0.9 \mathrm{mg} / \mathrm{mL}$ and $1.7 \mathrm{mg} / \mathrm{mL}$, the DPPH radical-scavenging rate both reached at $50 \%$. And when the mass concentrations were both $10 \mathrm{mg} / \mathrm{mL}$, the hydroxyl radical-scavengings were $35.8 \%$ and $27.9 \%$, respectively. Thus, it could be concluded that the antioxidant capacity in Jerusalem artichoke polysaccharides before overwintering was higher than that after overwintering, and showed a good dose-dependent manner with its mass concentration.
\end{abstract}

\section{INTRODUCTION}

Jerusalem artichoke (Helianthus tuberosus L.), also called Jiang Guizi, Yang Jiang, is a species of the Asteraceae family, genus Helianthus, originally grown in North America and later in China where it is introduced by Europe, and it has several advantages such as high growth rate, good tolerance to frost and drought and poor soil. The Jerusalem artichoke polysaccharide is also named inulin, as a natural carbohydrates which is soluble fiber and contains a short chain of fructose molecules as $\beta-2,1$ fructan, is abundant in the tubers, and has been used for bioethanol production. Modern pharmacological researches reported that Jerusalem artichoke has an effect on reducing blood glucose, serum cholesterol and triglycerides, improving insulin secretion, increasing absorption of calcium and magnesium and the number of bifidobacteria and lactobacilli in the colon [1]. Herein, inulin has a wide application prospects in food industry and medical care as a new ingredient. Previous studies showed plant polysaccharides, such as Ginger polysaccharide [2] and Lycium barbarum polysaccharide, have the beneficial for scavenging free radicals, inhibiting lipid oxidation and improving the capacity of antioxidant enzymes. Inulin had reported to have antioxidant capacity [3-4] and Jerusalem artichoke was mostly collected in the south and northwest parts of China. However, there is little information about Jerusalem artichoke in the northeast. Thus, we first collected Jerusalem artichoke before and after overwintering, and then investigated the link of the antioxidant capacity and different time.

\section{MATERIALS AND INSTRUMENTS}

Jerusalem artichoke before winter was collected from the suburb of Jilin City in Jilin Province in October 2017, after winter from the same area in April 2018. All reagents were analytically pure.

$752 \mathrm{~N}$ UV luminosity spectrophotometer was from Shanghai Jinghua Technology Instrument Co., Ltd. FA2004N electronic analysis balance was from Shanghai Precision Scientific Instrument Co., Ltd..

\section{Experiment method}

\subsection{Extraction process of inulin}

The Jerusalem artichoke was collected, washed, weighed and crushed, and then the mashed juice and pomace was added in distilled water to adjust to temperature $\left(90^{\circ} \mathrm{C}\right)$, time $(120 \mathrm{~min})$ and liquid-to-solid ratio (10:1). After extraction, the mixture was filtered to obtain filtrate and grounded into powders after freeze-drying. Inulin content was determined according to the phenol-sulfuric acid method with using glucose as reference standard [5].

\footnotetext{
*Corresponding author: zhl67@126.com
} 


\subsection{In vitro antioxidant capacity assay}

The inulin solutions with the different concentration were prepared respectively. All assays were measured in parallel for three times.

\subsubsection{Reducing power assay}

Add $10 \mathrm{~mL}$ of inulin solution was mixed with $2.5 \mathrm{~mL}$ of phosphate buffer solution $(0.2 \mathrm{~mol} / \mathrm{L}, \mathrm{pH}=6.6)$ and $1 \%$ potassium ferricyanide and incubated at $50{ }^{\circ} \mathrm{C}$ for $20 \mathrm{~min}$. After being cooled, $2.5 \mathrm{~mL}$ of $10 \%$ trichloroacetic acid solution was added and centrifuged at $3000 \mathrm{rpm}$ for 10 min. $2.5 \mathrm{~mL}$ of supernatant was mixed with $2.5 \mathrm{~mL}$ of distilled water and $0.5 \mathrm{~mL}$ of $0.1 \% \mathrm{FeCl}_{3}$ solution, then the absorbance was measured at $700 \mathrm{~nm}$. VC was served as positive control [6]. The concentrations of tested sample were replaced with $0.25,0.5,1.0,1.5$, and 2.0 $\mathrm{mg} / \mathrm{mL}$.

\subsubsection{DPPH radical-scavenging assay}

$1 \mathrm{~mL}$ of inulin solution was mixed with $2 \mathrm{~mL}$ of DPPH ethanol solution $(0.1 \mathrm{mmol} / \mathrm{L})$, and the absorbance at 517 $\mathrm{nm}$ after maintenance in the dark at room temperature for 30 min was measured. Reaction system without DPPH was applied as normal control, and system without tested sample was used as blank solution [7]. The concentrations of tested sample were replaced with 1, 5, 10,25 , and $50 \mathrm{mg} / \mathrm{mL}$.

\subsubsection{Hydroxyl radical-scavenging assay}

$1 \mathrm{~mL}$ of inulin solution was mixed with $1 \mathrm{~mL}$ of 0.75 $\mathrm{mmol} / \mathrm{L}$ phenanthroline and $2 \mathrm{~mL}$ of $\mathrm{PBS}(\mathrm{pH}=7.4)$. And then add $1 \mathrm{~mL}$ of distilled water, followed by addition of $1 \mathrm{~mL}$ of $0.75 \mathrm{mmoL} / \mathrm{L} \mathrm{FeSO}_{4}$. After being mixed, $1 \mathrm{~mL}$ of $0.12 \% \mathrm{H}_{2} \mathrm{O}_{2}$ was added for 60 min of incubation at 37 ${ }^{\circ} \mathrm{C}$, and the absorbance at $536 \mathrm{~nm}$ was determined [8]. The concentrations of tested sample were replaced with 2 , $4,6,8$, and $10 \mathrm{mg} / \mathrm{mL}$.

\section{Results and discussion}

\subsection{Determination of inulin}

The content of inulin before overwintering was $48.63 \%$ and after overwintering was $59.83 \%$. The latter sample was significantly higher than the former one. The main reason was that starch in Jerusalem artichoke for a long winter was converted into soluble sugars, which increaseing the content of inulin [9].

\subsection{Reducing power}

The reducing power can be associated with hydroxyl groups, which act as electron donors and react with free radicals to convert them to more stable products. Higher absorbance of the reaction mixture indicated greater reductive potential.

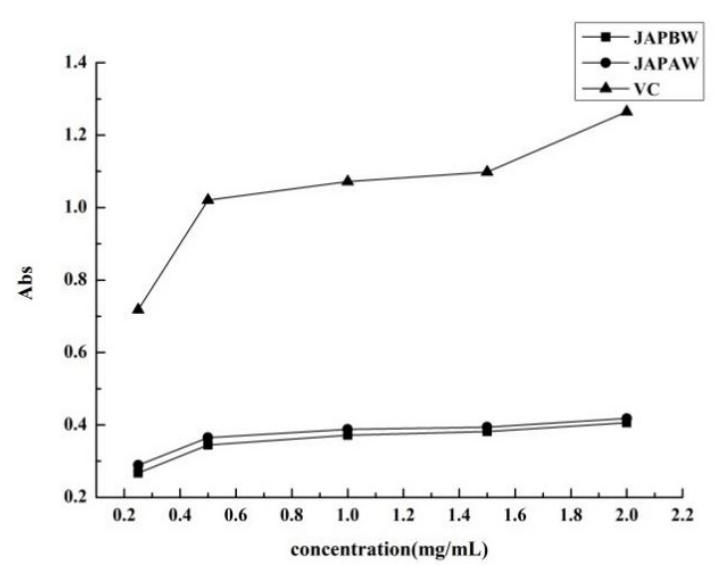

Fig. 1. Determination of inulin on reducing power

As shown in Figure 1, the reducing power of inulin solution slightly increased with increasing of constant concentration, but no significant difference was observed in the different solution and the absorbance values were about 0.3 . Furthermore, the inulin has weaker ability than $\mathrm{VC}$ on reducing power.

\subsection{DPPH radical-scavenging}

DPPH transfers either electron or hydrogen atom and neutralizes its free radicals. The possible mechanism of polysaccharides acting as an antioxidant may be attributed to their electron donation power to free radicals and thereby further terminating the radical chain reaction.

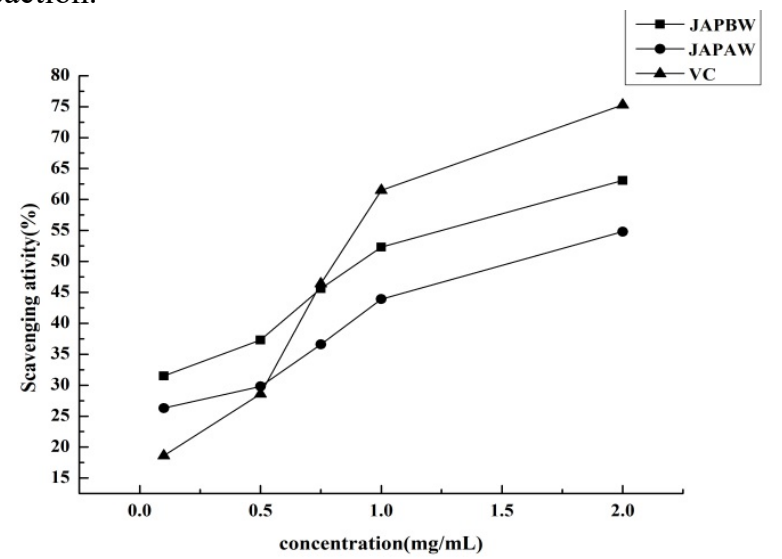

Fig. 2. Determination of inulin on DPPH radical-scavenging

The DPPH-scavenging rate increased with increasing of constant concentration (Fig. 3), which may attribute that inulin is a high polymer with multiple fructose groups linked by the same glycosidic bond and directly giving electrons [10]. It could be seen that inulin has a greater antioxidant capacity than $\mathrm{VC}$ at a low concentration. When the scavenging rate reached $50 \%$, the mass concentration of inulin after overwintering was $1.7 \mathrm{mg} / \mathrm{mL}$ and before wintering was $0.9 \mathrm{mg} / \mathrm{mL}$, which indicating that the latter one has significantly higher capacity.

\subsection{Hydroxyl radical-scavenging}

Hydroxyl radical can induce seriously oxidative damage of biological molecules such as nucleic acids, proteins and lipids, and hydroxyl radical-scavenging is an 
important index to reflect the antioxidant effect of the drug [11].

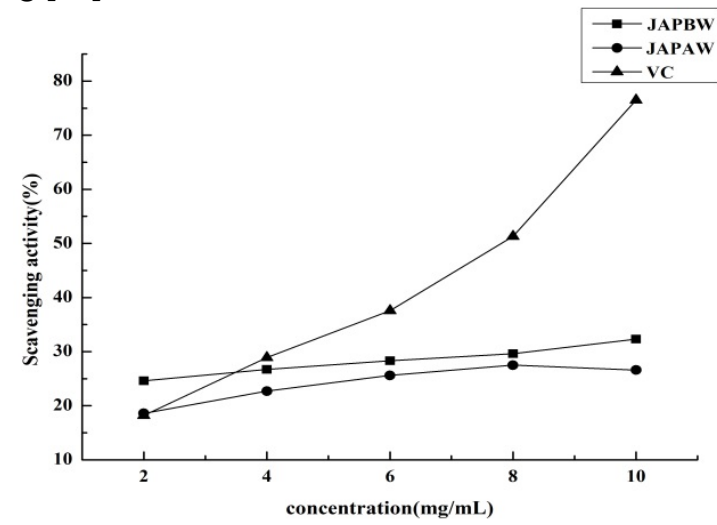

Fig. 3. Determination of inulin on hydroxyl radical-scavenging

The scavenging rate increased with increasing of constant concentration (Fig. 3). It could be seen that the scavenging rates of inulin before wintering were higher than those of the overwintering, especially at $10 \mathrm{mg} / \mathrm{mL}$, the difference was the most significant and reached 7.9 $\mathrm{mg} / \mathrm{mL}$. The scavenging capacity of inulin on hydroxyl radical was lower than $\mathrm{VC}$ at the same concentration which indicated the inulin has a higher antioxidant capacity.

\section{Conclusion}

In this study, the antioxidant capacity of inulin was determined by the in vitro antioxidant assays and increased in a dose-dependent manner. The nutritional components of Jerusalem artichoke overwintering in the northeast was affected by cold soil and less than $12 \mathrm{~h}$ of sunshine, which inducing the starch in the plant was converted into more sugar to resist cold and the antioxidant capacity of inulin after overwintering was lower. Although some studies on the cultivation and use of inulin were reported [12-13], the correlation on different variety, regions, period with linking the antioxidant capacity in vivo and vitro are still unclear. Herein, all factors should be comprehensively taken into consideration in the further research, which promoting the industrial production.

\section{References}

1. R. Karimi, M.H. Azizi, M. Ghasemlou, M. Vaziri, Carbohyd. Polym 119, 85-100 (2015)

2. Y. Wang, X. Wei, F. Wang, J. Xu, X. Tang, N. Li, Int. J. Biol. Macromo 111, 862-869 (2018)

3. R. Luo, X. Song, Z. Li, A. Zhang, X. Yan, Q. Pang, Plant. Physiol. Bioch 125, 27-34 (2018)

4. I.B. Gunnarsson, S.E. Svensson, E. Johansson, D. Karakashew, I. Angelidaki, Ind. Crop. Prod 56, 231-240 (2014)

5. Y.G. Wang, F. Wang, X.Q. Ma, S.C. Sun, F.F. Leng, W.J. Zhang, X.L. Wang, Ind. Crop. Prod 77, 467-475 (2015)
6. H.C. Ting, Y.W. Hsu, C.F. Tsai, F.J. Lu, M.C. Chou, W.K. Chen, Food. Chem 125, 652-659 (2011)

7. B. Ren, C. Chen, C. Li, X. Fu, L. You, R.H. Liu, Carbohyd. Polym 173, 192-201 (2017)

8. J.H. Wang, J.L. Xu, J.C. Zhang, Y. Liu, H.J. Sun, X.Q. Zha, Carbohyd. Polym 131, 240-247 (2015)

9. Y.Y. Wang, Y.N. Hu, S.H. Fan, X.H. Liu, X.S. Wang, Acad. Period. Fram. Prod. Process 13-16 (2013)

10. C. Yin, X. Fan, Z. Fan, D. Shi, H. Gao, Int. J. Biol. Macromo 111, 446-454 (2018)

11. S. Marklund, G. Marklund, Eur. J. Biochem 47, 469-474 (2005)

12. N. Worawuthiyanan, W. Vanichsriratana, P. Srinophakun, T. Sajjaanantakul, S. Sirisansaneeyakul, World. J. Microb. Biot 23, 543-552 (2007)

13. L. Yang, Q.S. He, K. Corscadden, C.C. Udenigwe, Plant. Biotechnol. Rep 5, 77-88 (2015) 